\title{
Shape recovery in a thermoset shape memory polymer and its fabric-reinforced composites
}

\author{
J. Ivens ${ }^{1,2^{*}}$, M. Urbanus ${ }^{2}$, C. De Smet ${ }^{3}$ \\ ${ }^{1}$ Department of Applied Engineering, Lessius University College, Campus De Nayer, J. De Nayerlaan 5, B-2860 \\ Sint-Katelijne Waver, Belgium \\ ${ }^{2}$ Department of Metallurgy and Materials Engineering, Katholieke Universiteit Leuven, Kasteelpark Arenberg 44, B-3001 \\ Leuven, Belgium \\ ${ }^{3}$ Sint-Lucas Architectuur, Hogeschool voor Wetenschap en Kunst, Hoogstraat 22, B-9000 Gent, Belgium
}

\begin{abstract}
A shape memory polymer (SMP) can be deformed from a permanent to a temporary shape above their transformation temperature. Upon reheating, the SMP spontaneously returns to the permanent shape. SMP's show high deformability, but the recovery stresses are very low, thus limiting the size of the components. This paper presents the first results of an ongoing research to develop large sized components based on SMP. To achieve higher recovery stresses, asymmetric fibre reinforced shape memory composites were produced (SMPC) using resin transfer moulding. The results show a 30fold increase in recovery stress, compared to the neat SMP resin. The recovery stress is independent of the deformation temperature, but is strongly affected by the degree of deformation. At higher deformation levels, crazing occurs. Even though the visible effects of the crazing disappear during reheating, it does influence the recovery stress. This indicates that the ability to recover the permanent shape might change in cyclic loading. All composites tested show complete recovery upon reheating. The rate of shape recovery is higher when the fibre reinforcement is loaded in compression.
\end{abstract}

Keywords: polymer composites, smart polymers, material testing

\section{Introduction}

Most shape memory materials are defined by one permanent and one temporary shape (one-way transformation) or two permanent shapes (two-way transformation). A trigger - usually heat - can induce the change from one (temporary or permanent) shape to another (permanent) shape. The shape transformation and the work done during the transformation are determined by the release of the energy, stored inside the material. Shape memory effects are found in metals, ceramics and polymers, of which the metallic shape memory alloys (SMA) like Nitinol are the most widely used, as they combine a high level of recovery stress with a reasonable deformation [1].
Shape memory polymers can be a thermoplastic, a thermoset or an elastomeric material; they exhibit much higher levels of deformation than SMA. The transformation temperature of an SMP can be the melting temperature or the glass transition temperature of a 'soft' phase [2].

For a thermoset SMP, the transformation temperature is the glass transition temperature $T_{\mathrm{g}}$. One type of SMP is a single phase material, consisting of polymer chains with a certain (limited) number of cross-links [2-5]. The cross-links are net points, where the memory of the permanent shape is stored, while the free polymer chains between the crosslinks are switching segments that obtain increased mobility above $T_{\mathrm{g}}$. Upon deformation, the mobile

\footnotetext{
*Corresponding author, e-mail: jan.ivens@mtm.kuleuven.be
} (c) BME-PT 
polymer chain segments are stretched in the loading direction, resulting in a decreased entropy; at the same time, the net points elastically deform; the overall result is an increase in enthalpy of the SMP. When the material is allowed to cool down in deformed state, the loss of mobility of the polymer chain segments in the switching segments stabilizes the temporary shape.

A second type of SMP is a two phase material that both form an interconnected 3-dimensional network $[6,7]$. The elastic energy is stored in the hard phase, and is responsible for the recovery of the permanent shape, while the soft phase, upon heating above its transformation temperature (often its melting temperature), enables the deformation to a temporary shape.

The major drawback of shape memory polymers is the low recovery stress (Figure 1), limiting the size of commercial components to a few centimetres: the recovery stress of larger components is insufficient to counter the components weight. The solution consists of reinforcing the SMP with particles or fibres. The addition of carbon nanotubes results in a 50 to $100 \%$ increase of the recovery stress and improved conductivity but the expense of a reduced shape recovery effect [8-10]. Alternative particle reinforcements like $\mathrm{SiC}$ [11] and carbon black [12] are less effective.

Some research on fibre reinforced SMP laminates has been reported. The fibre reinforcement dramatically increases the recovery stress [13]. Gall et al. [14] found only a limited effect of the fibre reinforcement on the recovery ratio, however the elastic spring back increased significantly. These results indicate that the stored elastic energy is an important factor in the shape memory effect. The same authors also showed that microbuckling is important in the high temperature deformation; their observations seem to indicate that the microbuckling is reversible [14]. Zhang et al. [15] evaluated asymmetric SMPC in bending and observed that SMPC with the fibre reinforcement under compression exhibited a faster recovery, a higher recovery ratio and a higher recovery stress. Continuous fibre reinforcement strongly affects the deformation limits of the SMP: under tension in the fibre direction, the shape memory effect is totally lost. Although some small size applications have been developed [13, $16]$, there is a need for more research on continuous

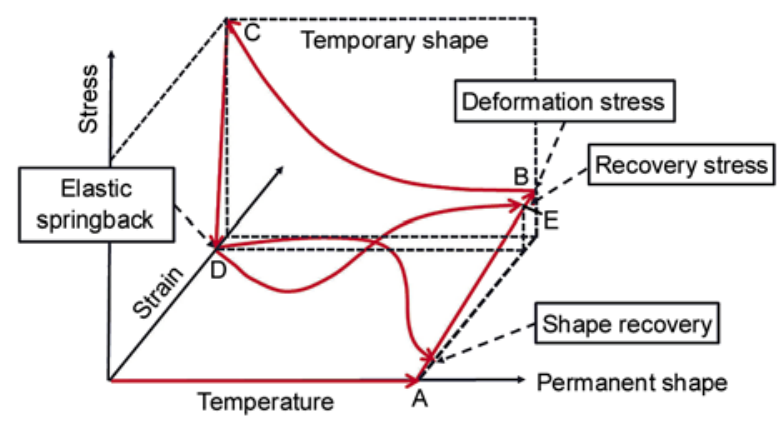

Figure 1. The thermomechanical cycle, describing the behaviour of an SMP. After heating to temperature $T_{\mathrm{h}}(\mathrm{A})$, the material is deformed (B) and subsequently cooled (C). Elastic springback results in a change in strain (D). Upon unconstrained reheating to $T_{\mathrm{h}}$, the material returns to (A). If the temporary shape is constrained, heating results in a stress build up (E), the recovery stress.

fibre reinforced polymer composites to develop functioning large SMPC objects.

\section{Materials and test methods \\ 2.1. Materials}

The material used in this research is Veriflex VF62 of CRG Industries (Dayton, $\mathrm{OH}$ ). This thermoset styrene-based resin, is cured with benzoyl peroxide in a $24: 1$ ratio. Neat resin plates were produced by casting the reactive resin in a $4 \mathrm{~mm}$ thick mould cavity. The resin was cured according to the following cure cycle:

- Heat to $75^{\circ} \mathrm{C}$ with a heating rate of $1^{\circ} \mathrm{C} / \mathrm{min}$.

- Maintain $75^{\circ} \mathrm{C}$ during 3 hours.

- Heat to $90^{\circ}$ with a heating rate of $5^{\circ} \mathrm{C} /$ hour.

- Heat to $110^{\circ} \mathrm{C}$ with a heating rate of $10^{\circ} \mathrm{C} /$ hour.

The properties of the neat Veriflex VF62 resin are presented in Table 1. The transformation temperature was determined by the glass transition temperature of the cured resin using Dynamic Mechanical Thermal Analysis (TA Instruments Q800). An oscillation of $1 \mathrm{~Hz}$ with a strain amplitude of $0.05 \%$ strain was imposed in a three-point bending set-up, using a span length of $34 \mathrm{~mm}$, while the temperature is increased to $95^{\circ}$ with a heating rate of $2^{\circ} \mathrm{C} / \mathrm{min}$.

Table 1. Properties of Veriflex CF62

\begin{tabular}{|l|c|}
\hline Tensile strength & $23.00 \mathrm{MPa}$ \\
\hline Compression strength & $32.40 \mathrm{MPa}$ \\
\hline E-modulus & $1.24 \mathrm{GPa}$ \\
\hline Strain to failure & $3.90 \%$ \\
\hline$T_{\mathrm{g}}: \operatorname{loss}$ modulus & $62^{\circ} \mathrm{C}$ \\
$\tan \delta$ & $75^{\circ} \mathrm{C}$ \\
\hline
\end{tabular}




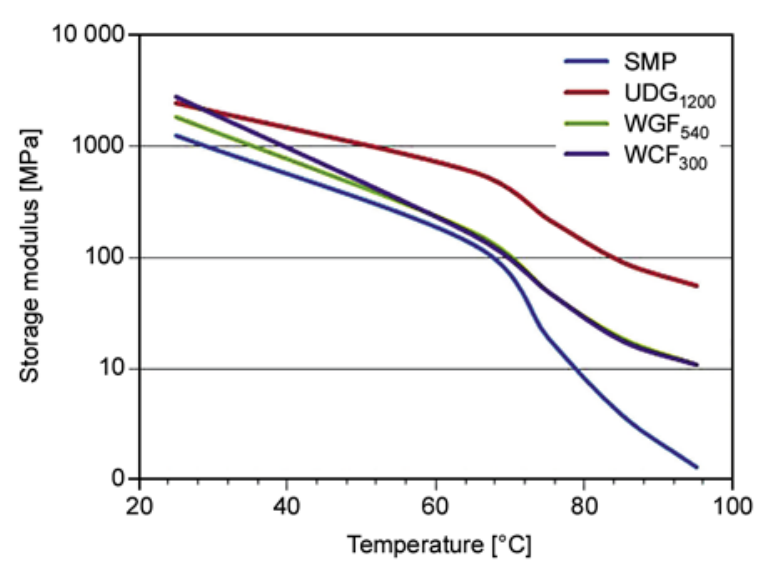

Figure 2. Storage modulus as a function of temperature, determined by dynamic mechanical analysis

Three types of fibre reinforcements were selected: a quasi-unidirectional non-crimp E-glass fabric (UDG1200; areal weight $1200 \mathrm{~g} / \mathrm{m}^{2}$, supplier: Saertex, Germany), an E-glass plain woven fabric (WGF540; areal weight $540 \mathrm{~g} / \mathrm{m}^{2}$ supplier: SaintGobain Technical Fabrics, Belgium) and a T300 carbon fibre twill-weave (TWC300; areal weight $300 \mathrm{~g} / \mathrm{m}^{2}$, supplier Hexcel Reinforcements, France). Composite plates were produced using resin transfer moulding in a heated aluminium mould, containing a single layer of reinforcement. The resulting plate thickness of $3.2 \mathrm{~mm}$ resulted in fibre volume fractions of $16.5 \%$ (UDG1200), $7.7 \%$ (WGF540) and 5\% (TWC300) respectively. Because the fabric thickness is lower than the plate thickness, the fabric was held against the mold surface to avoid 'swimming'. Consequently, the resulting composite is asymmetric. Figure 2 shows the evolution of the storage modulus as a function of temperature. The storage modulus at room temperature is low, because of the low fibre volume fraction of the specimens, and because the modulus was determined in a short span three-point bending test, where shear deformations cannot be neglected. Moreover, the storage modulus is an apparent modulus: since the laminates are asymmetric, engineering constants are undefined.

\subsection{Test methods}

The deformation-cooling-reheating cycle of SMP and SMPC samples was determined in a single cantilever beam test on small samples using the same TA Instruments Q800 equipment, in static mode (TMA). The temperature-strain cycle and the resultant stress are shown in Figure 3. UDG1200 SMPC

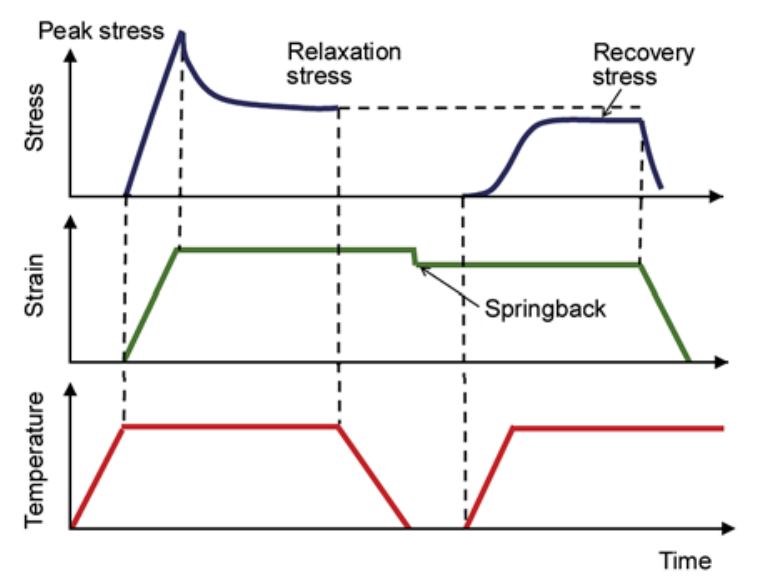

Figure 3. Temperature-strain cycle of the TMA experiments: the specimen is heated at $3^{\circ} \mathrm{C} / \mathrm{min}$ to the deformation temperature. The specimen is deformed $(3 \% / \mathrm{min})$ to a set maximum strain and held for 30 minutes to allow stress relaxation. The specimen is cooled down in deformed state. The residual stress is removed and the elastic spring back is recorded. The restrained specimen is reheated $\left(3^{\circ} \mathrm{C} / \mathrm{min}\right)$ to $75^{\circ} \mathrm{C}$, while the recovery stress is measured. Finally, the specimen is returned to the permanent shape.

and pure SMP specimens $-17 \mathrm{~mm} \times 10 \mathrm{~mm} \times 3 \mathrm{~mm}$ - were deformed to a strain of $10 \%$ at $75^{\circ} \mathrm{C}$. Additional tests up to $20 \%$ deformation at $75^{\circ} \mathrm{C}$ and $10 \%$ deformation at $65^{\circ} \mathrm{C}$ and $85^{\circ} \mathrm{C}$ were performed on UDG1200 SMPC (§ 3.1).

Due to the small specimen size for TMA testing, the shape memory cycle was repeated on larger $(80 \mathrm{~mm} \times$ $20 \mathrm{~mm} \times 3 \mathrm{~mm}$ ) UDG1200 SMPC specimens, loaded in three point bending with a span length of $50 \mathrm{~mm}$. Specimens were heated using silicone oil, while they were cooled in air. Different maximum strain levels were used, and specimens were subjected to multiple cycles to evaluate the repeatability of shape recovery and the effect of local damage on the recovery stress $(\S 3.2)$.

The recovery rate and ratio were measured using a similar set-up as Gall et al. [14], shown in Figure 4 (§3.3). A flat specimen is heated and subsequently deformed on a tubular surface, where it is allowed to cool down. During reheating, the shape recovery (via the angle between the two specimen ends) is measured as a function of the recovery time. The SMP and the three SMPC materials were tested at $75^{\circ} \mathrm{C}$ with $33 \%$ flexural strain. Two deformation levels and two deformation temperatures were used for UDG1200. Tests were performed with the fabric 


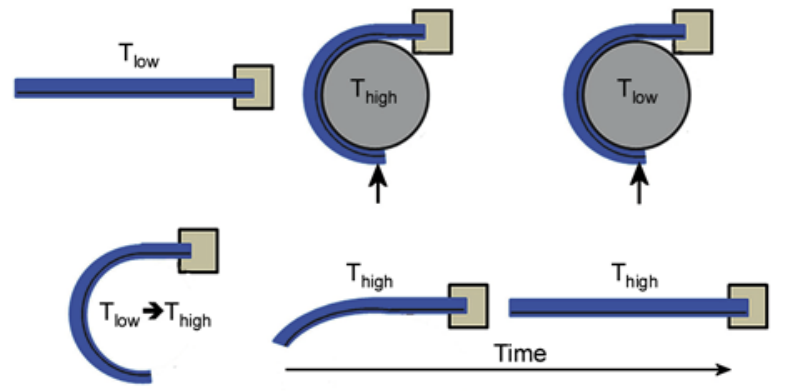

Figure 4. A specimen is deformed to a preset radius at high temperature and constrained during deformation. The specimen is reheated, and it gradually returns to its permanent flat shape. The recovery rate and ratio are measured. The position of the fabric is indicated by the grey line in the specimen: in this picture, the fabric is on the compressive side of the laminate.

at the compressive side (as shown in Figure 4) and on the tensile side of the specimen.

\section{Results and discussion}

\subsection{Deformation and recovery stress}

Figure 5, obtained from the TMA-experiments, shows the variation of the stress during the deformation phase and the reheating phase of UDG1200 SMPC. During the deformation, the stress builds

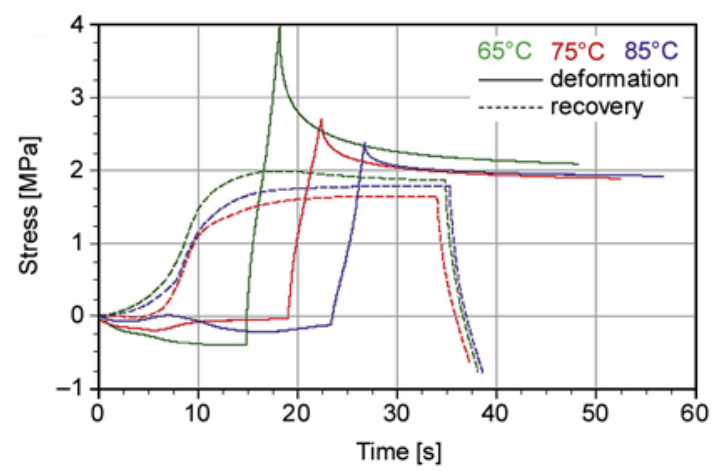

Figure 5. Stress as a function of time during the deformation phase (solid lines) and the recovery phase (dashed lines) of UDG1200 SMPC, for different deformation temperatures rapidly, reaching a peak stress, followed by stress relaxation, evolving to a plateau value. During the reheating to $75^{\circ}$, the specimen builds up recovery stresses. Table 2 shows the numerical data, extracted from the curves, for neat SMP and for the different SMPC. UDG1200 SMPC was tested at different deformation temperatures and deformation levels. The characteristics are defined in Figure 3. The UDG1200 specimens were submitted to a second deformation reheating cycle, as indicated by (2).

The results of the experiments on UDG1200 show a decrease of the peak stress as the deformation temperature increases. The peak stress is caused by the resistance to deformation in the cross-linked net points and in the (linear) switching segments of the material. At $65^{\circ} \mathrm{C}$ - below the transformation temperature - the switching segments still have some stiffness. The peak stress drops significantly when the $T_{\mathrm{g}}$ is exceeded. All specimens exhibit stress relaxation. The viscous nature of the switching segments is responsible for the relaxation, but the stress does not decay to zero: a plateau value is reached; it is related to the built-up internal stresses by the rigid net points of the polymer and its level is indicative of the stored energy. The plateau stress is independent of the deformation temperature. For $10 \%$ deformation, the relaxation stress is $1.75 \mathrm{MPa}$. During reheating of the constrained specimen, recovery stresses are built up. The effect of the deformation temperature on the recovery stress is insignificant. The recovery stress level is $1.65 \mathrm{MPa}$ for $10 \%$ deformation, i.e. $94 \%$ of the plateau stress level during the deformation stage. Compared with the neat resin, the relaxation and recovery stresses are increased 30 -fold by the addition of the 13\% glass fibre reinforcement!

The stress levels in the other composites are significantly lower. This is mainly caused by the difference in fibre volume fraction, as shown in Figure 6.

Table 2. Numerical data, obtained from the TMA experiments. $75^{\circ}(2)$ indicates a second deformation - reheating cycle

\begin{tabular}{|c|c|c|c|c|c|c|}
\hline & \multicolumn{2}{|c|}{ TMA results } & \multirow[b]{2}{*}{$\begin{array}{c}\text { Peak stress } \\
\text { [MPa] }\end{array}$} & \multirow[b]{2}{*}{$\begin{array}{c}\text { Relaxation stress } \\
{[\mathrm{MPa}]}\end{array}$} & \multirow[b]{2}{*}{$\begin{array}{c}\text { Spring back } \\
{[\%]}\end{array}$} & \multirow[b]{2}{*}{$\begin{array}{c}\text { Recovery stress } \\
\text { [MPa] }\end{array}$} \\
\hline & $\begin{array}{c}\text { Strain } \\
{[\%]}\end{array}$ & $\begin{array}{c}\text { Temperature } \\
{\left[{ }^{\circ} \mathrm{C}\right]}\end{array}$ & & & & \\
\hline SMP & $10 \%$ & $75^{\circ} \mathrm{C}$ & $0.085 \pm 0.005$ & $0.05 \pm 0.01$ & $0.025 \pm 0.005$ & $0.05 \pm 0.01$ \\
\hline TWC300 & $10 \%$ & $75^{\circ} \mathrm{C}$ & 0.5 & 0.3 & 0.07 & 0.3 \\
\hline WGF540 & $10 \%$ & $75^{\circ} \mathrm{C}$ & $1.0 \pm 0.1$ & $0.62 \pm 0.05$ & $0.16 \pm 0.03$ & $0.55 \pm 0.03$ \\
\hline \multirow{5}{*}{ UDG1200 } & \multirow{3}{*}{$10 \%$} & $65^{\circ} \mathrm{C}$ & $3.65 \pm 0.45$ & $1.95 \pm 0.15$ & $0.45 \pm 0.35$ & $1.65 \pm 0.3$ \\
\hline & & $75^{\circ} \mathrm{C}$ & $2.4 \pm 0.2$ & $1.75 \pm 0.12$ & $0.25 \pm 0.10$ & $1.60 \pm 0.06$ \\
\hline & & $85^{\circ} \mathrm{C}$ & $2.2 \pm 0.2$ & $1.75 \pm 0.15$ & $0.15 \pm 0.05$ & $1.65 \pm 0.12$ \\
\hline & $20 \%$ & $75^{\circ} \mathrm{C}$ & $5.9 \pm 1.3$ & $3.9 \pm 0.5$ & $2 \pm 1$ & $3 \pm 1$ \\
\hline & $20 \%$ & $75^{\circ} \mathrm{C}(2)$ & $4.5 \pm 0.7$ & $3.4 \pm 0.4$ & $1.5 \pm 1.5$ & $2.5 \pm 0.7$ \\
\hline
\end{tabular}




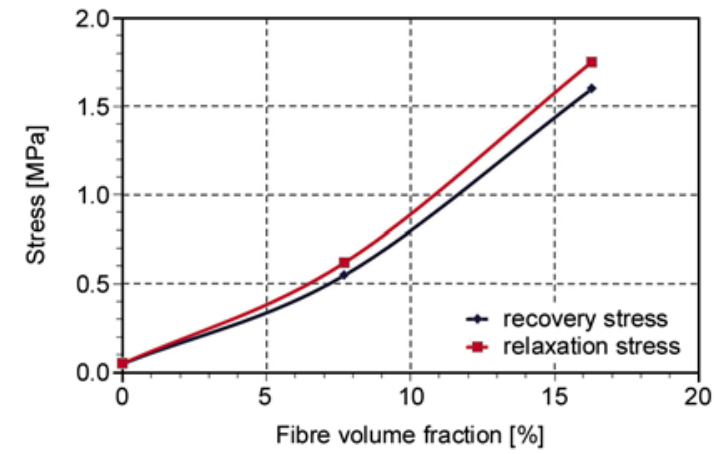

Figure 6. Recovery and relaxation stress as a function of the fibre volume fraction for the different glass fibre reinforced composite materials

It must be pointed out that more experiments are needed to discriminate between glass and carbon composites.

\subsection{Repeatability and effect of damage}

Table 2 shows that the recovery ratio decreases with increasing deformation strain. This is due to the increased elastic spring back and due to damage: the TMA specimens deformed up to $20 \%$ strain showed stress whitening after cooling and unloading. Stress whitening was also observed during the larger scale three point bending tests. These experiments focused on repeated deformation-reheating cycles. For each cycle, the maximum flexural strain was increased. The flexural stress during deformation is presented in for 4 consecutive cycles. Stress whitening was observed at a much lower strain level (3.6\%) in comparison with the small TMAsamples.

Stress whitening is caused by crazing in the switching segments of the SMP. Kasajima et al. [17] have observed that stress whitening created at low strain

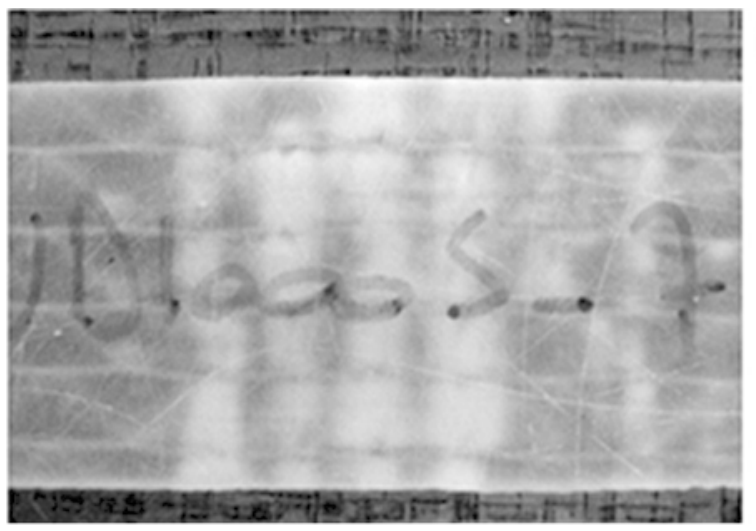

a) levels disappears upon unloading. Higher strain levels result in residual stress whitening, but Kasajima et al. showed that stress whitening can be removed by heating. This was corroborated by the authors observations on the SMPC specimens: the stress whitening in the $4 \%$ strained specimens disappeared after recovery heating, while for the 7.5 and $11 \%$ deformation levels, prolonged heating was needed to remove the stress whitening (Figure 7).

Although these observations seem to suggest that the effects of stress whitening are recoverable, this is not correct. Kasajima observed a decrease in yield strength after deformation and subsequent reheating to remove the stress whitening. Similar results were obtained in three point bending (Figure 8): a clear drop in yield stress is observed between the first and the second cycle, yet the additional drop from the second to the third cycle is much smaller. Repeating the same deformation in the fourth cycle gave the same stress strain curve. It can therefore not be excluded that the effects of the

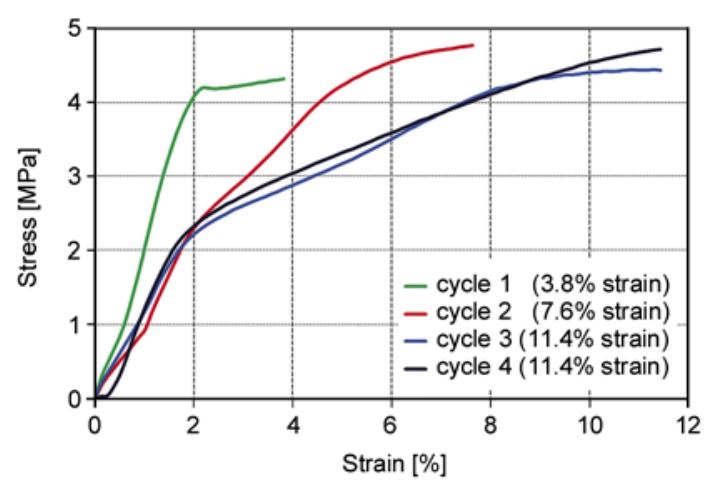

Figure 8. Flexural stress-strain curves at the transformation temperature for UDG1200 SMPC. The same sample was loaded in a cyclic manner. Each curve present the loading curve of a cycle.

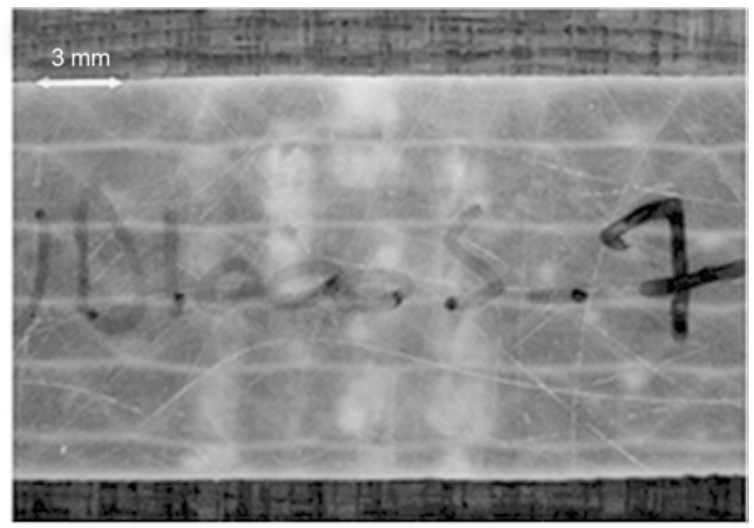

b)

Figure 7. Stress whitening in the UDG1200 specimens, loaded in three-point bending. More stress whitening is visible directly after recovery (a). Most stress whitening disappears after 30 minutes at elevated temperature (b). 
stress whitening are not fully reversed, and this could also be responsible for the lower recovery stress to relaxation stress ratio (Table 2). An additional reduction in recovery stress during a second load cycle was found, similar to Kasjima's observations. Further research is necessary to establish the effect of repeated deformation and shape recovery on the recovery stress and the recovery rate.

\subsection{Recovery ratio and rate}

The recovery ratio and rate were measured using the set-up shown in Figure 4. Figure 9 and 10 shows the recovery angle as a function of time for for the different materials tested. All composite specimens exhibit full recovery, while the neat SMP is unable to recover the permanent shape. The overall recovery rates are low, compared to what is found in shape memory metal alloys. A higher stiffness results in a faster shape change. Figure 10

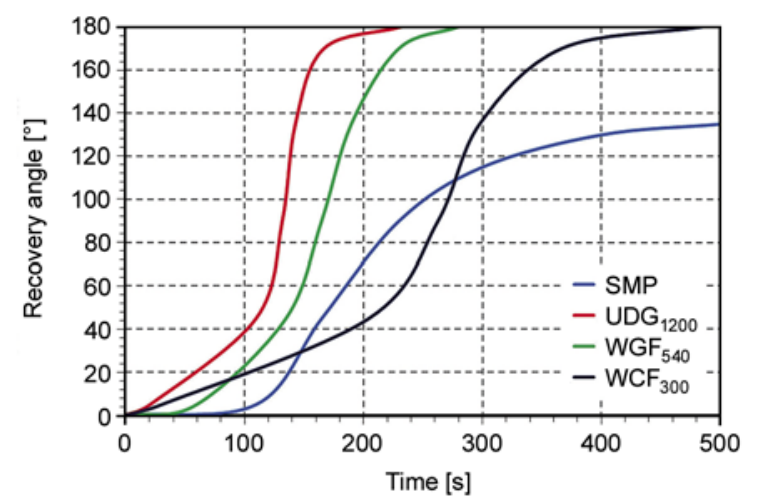

Figure 9. Recovery angle as a function of time for the neat SMP and for the fabric reinforced composites, measured using the set-up shown in Figure 4. All composites show complete shape recovery, while the neat SMP is unable to counteract gravity. shows the effect of temperature and deformation level on the recovery rate. A higher temperature and a higher deformation strain result in slower recovery; the effect of strain is small.

Figure 11 shows the effect of the asymmetry on the shape recovery of the carbon fabric TWC 300 SMPC. A much higher recovery rate is found if the fabric is located in the compressive side on the test

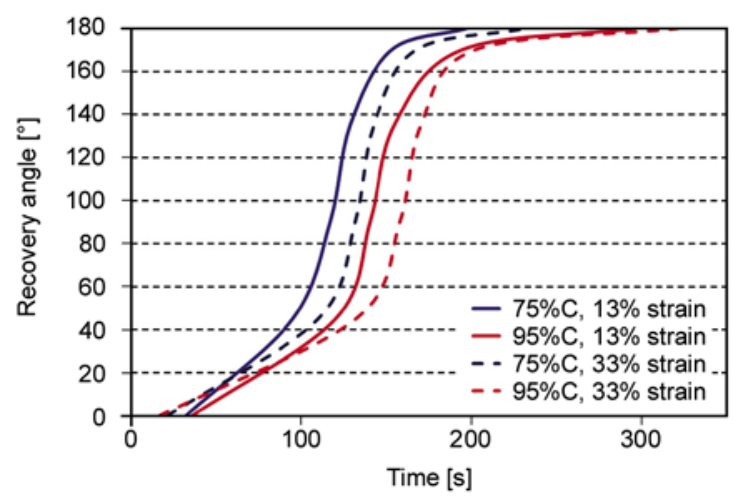

Figure 10. Recovery angle as a function of time for the UDG1200 SMPC. Different flexural strains and temperatures were used.

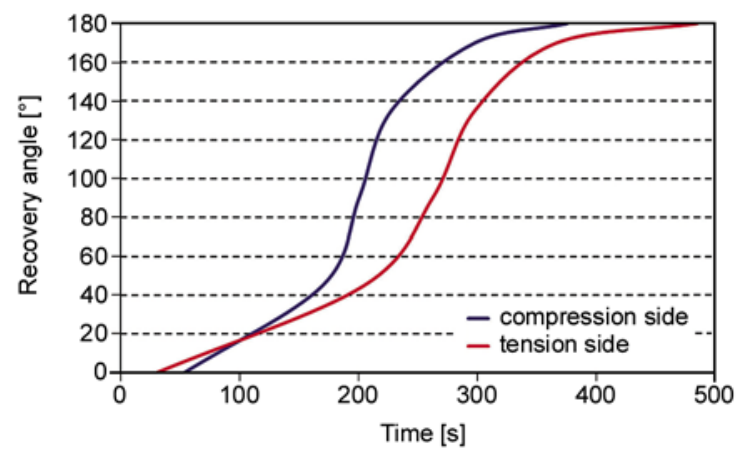

Figure 11. Recovery angle as a function of time for the TWC300 SMPC, with the reinforcement layer in the compressive side and in the tensile side of the specimen (temperature $75^{\circ} \mathrm{C}$ )

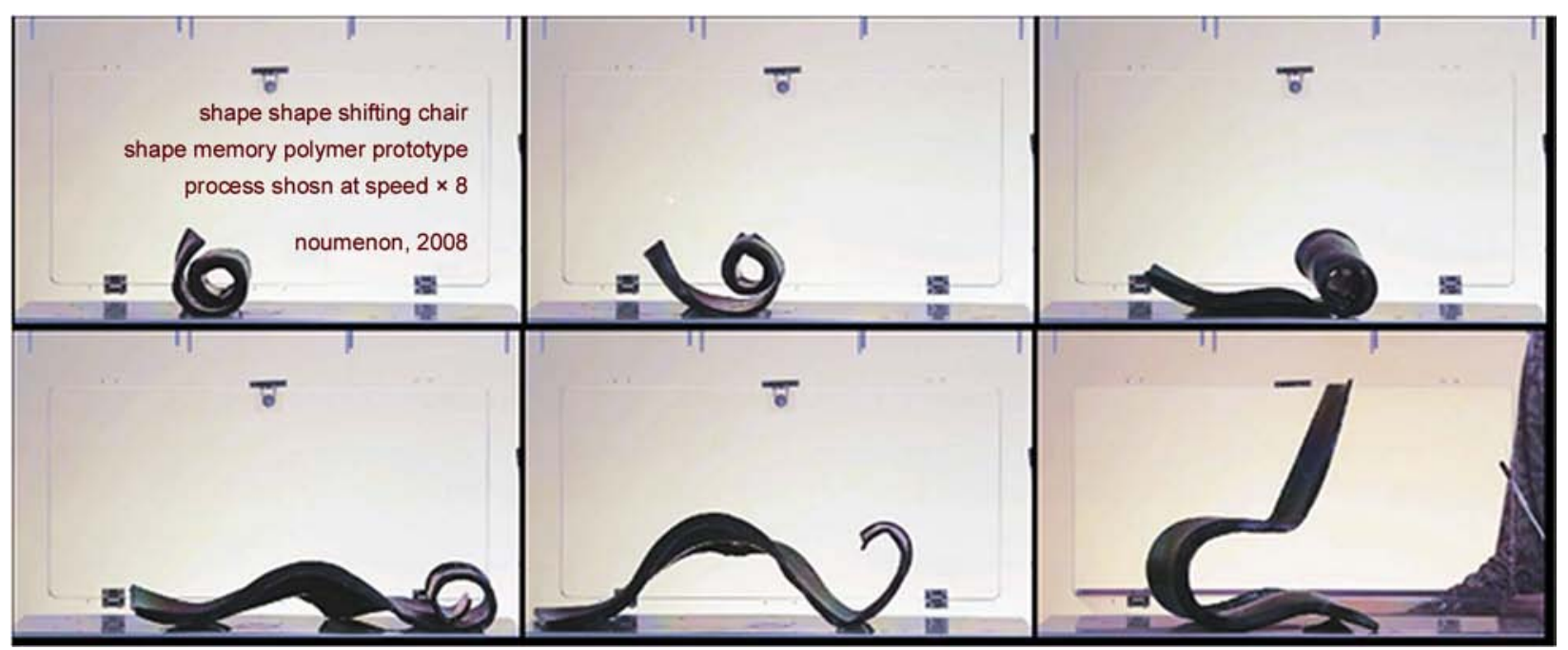

Figure 12. Shape recovery of a model chair (height $250 \mathrm{~mm}$ ), made of UDG1200-Veriflex VF62 
specimen. Similar observations were made by Zhang et al. [15]. An explanation for this difference has not been found. Moreover, the recovery stress is lower when the fabric is in the compressive side of the specimen.

The much higher recovery stress of SMPC has enabled the authors to produce a $250 \mathrm{~mm}$ high 'chair'. A single layer of UDG1200 was placed in an aluminium mould and the composite was manufactured using vacuum assisted transfer moulding. The permanent shape can be deformed to any temporary shape. Reheating using hot air results in shape recovery, as shown in Figure 12 (movie available in www.youtube.com/watch?v=GTLwExvDVVw). The recovery rate is very low, the full shape recovery takes almost 10 minutes. To obtain functional components, the recovery rate must be improved, by increasing the thermal or electrical conductivity.

\section{Conclusions}

This paper presented the first results of ongoing experimental work to determine the effect of fibre reinforcement on the transformation of a thermoset shape memory polymers. The following conclusions can be drawn:

- The recovery stress of the SMPC with unidirectional glass fibre reinforcement, loaded in bending, is 30 higher than for the neat SMP resin.

- The recovery stress is independent of the deformation temperature.

- The recovery stress is strongly affected by the degree of deformation.

- High deformation levels result in crazing (stress whitening). Even though the stress whitening disappears after reheating, it does influence the recovery stress.

- All composites tested show complete shape recovery. The SMP material is unable to recover the permanent shape against the forces of gravity.

- The rate of shape recovery is higher when the fibre reinforcement is loaded in compression.

- A model sized SMPC chair was successfully produced and the shape recovery was proved, although the recovery time was long.

\section{References}

[1] Van Humbeeck J.: Non-medical applications of shape memory alloys. Materials Science and Engineering A, 273-275 134-148 (1989).

DOI: $10.1016 / \mathrm{S} 0921-5093(99) 00293-2$

[2] Ratna D., Karger-Kocsis J.: Recent advances in shape memory polymers and composites: A review. Journal of Materials Science, 43, 254-269 (2008). DOI: $10.1007 / \mathrm{s} 10853-007-2176-7$

[3] Rousseau I.: Challenges of shape memory polymers: A review of the progress toward overcoming SMP's limitations. Polymer Engineering and Science, 48, 20752089 (2008).

DOI: $10.1002 /$ pen.21213

[4] Takei S.: What is shape-memory polymer (in Japanese). in 'Development and application of shape memory polymers' (ed.: Irie M.) CMC, Tokyo, 10-88 (1989).

[5] Liu Y., Gall K., Dunn M., Greenberg A., Diani J.: Thermomechanics of shape memory polymers: Uniaxial experiments and constitutive modeling. International Journal of Plasticity, 22, 279-313 (2006).

DOI: $10.1016 /$ j.ijplas.2005.03.004

[6] Zhang H., Wang H., Zhong W., Du Q.: A novel type of shape memory polymer blend and the shape memory mechanism. Polymer, 50, 1596-1601 (2009).

DOI: $10.1016 /$ j.polymer.2009.01.011

[7] D’Hollander S., Van Assche G., Van Mele B., Du Prez F.: Novel synthetic strategy toward shape memory polyurethanes with a well-defined switching temperature. Polymer, 50, 4447-4454 (2009). DOI: $10.1016 /$ j.polymer.2009.07.021

[8] Meng Q., Hu J.: A review of shape memory polymer composites and blends. Composites Part A: Applied Science and Manufacturing, 40, 1661-1672 (2009). DOI: 10.1016/j.compositesa.2009.08.011

[9] Koerner H., Price G., Pearce N. A., Alexander M., Vaia R. A.: Remotely actuatedpolymer nanocompositesstress-recovery of carbon-nanotube-filled thermalplastic elastomers. Nature Materials, 3, 115-120 (2004). DOI: $10.1038 /$ nmat1059

[10] Ni Q-Q., Zhang C. S., Fu Y. Q., Dai G. Z., Kimura T.: Shape memory effect and mechanical properties of carbon nanotube/shape memory polymer nanocomposites. Composite Structures, 81, 176-184 (2007). DOI: $10.1016 /$ j.compstruct.2006.08.017

[11] Gall K., Dunn M., Finch D., Lake M., Munshi N.: Shape memory polymer nanocomposites. Acta Materialia, 50, 5115-5126 (2002). DOI: $10.1016 / \mathrm{S} 1359-6454(02) 00368-3$

[12] Gunes I., Cao F., Jana S.: Evaluation of nanoparticulate fillers for development of shape memory polyurethane nanocomposites. Polymer, 49, 2223-2234 (2008). DOI: $10.1016 /$ j.polymer.2008.03.021 
[13] Lan X., Liu Y., Lv H., Wang X., Leng J., Du S.: Fiber reinforced shape-memory polymer composite and its application in a deployable hinge. Smart Material Structures, 18, 024002/1-024002/6 (2009).

DOI: $10.1088 / 0964-1726 / 18 / 2 / 024002$

[14] Gall K., Mikulas M., Munshi N., Beavers F., Tuppers M.: Carbon fiber reinforced shape memory polymer composites. Journal of Intelligent Material Systems and Structures, 11, 877-887 (2000).

DOI: 10.1106/EJGR-EWNM-6CLX-3X2M
[15] Zhang C-S., Ni Q-Q.: Bending behaviour of shape memory polymer based laminates. Composite Structures, 78, 153-161 (2007).

DOI: $10.1016 /$ j.compstruct.2005.08.029

[16] Barrett R., Taylor R., Keller P., Codell D., Adams L.: Deployable reflectors for small satellites. in ' $21^{\text {st }}$ Annual Conference on Small Satellites AIAA, Logan, USA' 1-9 (2007).

[17] Kasajima M., Ito K., Tsutsui M.: Stress-whitening phenomenon and relaxation behavior therefore (in Japanese). Bulletin of the Technical College of Hosei University, 18, 33-48 (1982). 